\title{
Multiple Transcription Factors in the 5'-Flanking Region of the Human Polymeric Ig Receptor Control its Basal Expression
}

Short Title: The human polymeric Ig receptor promoter

R. Sergio Solorzano-Vargas ${ }^{3}$, Jiafang Wang, Lingling Jiang, Hugh V. Tsai, Luis O. Ontiveros, Mukta A. Vazir², Renato J. Aguilera², Martín G. Martín.

Departments of Pediatrics, Division of Gastroenterology and Nutrition, and Molecular Cellular and Developmental Biology ${ }^{2}$, University of California Los Angeles School of Medicine, Los Angeles, 90095; and ${ }^{3}$ Department of Biology, California State University Northridge, California, 91330

Grant Support: This research was supported by grants from the National Institutes of Health (HD-34706) and the Crohn's and Colitis Foundation of America (Grant \# 016714).

Abbreviations: IRS, inverted repeat sequence; USF, upstream stimulatory factor; ISRE, interferon response element; IRF-1, interferon response factor-1; USF1 and 2, upstream stimulatory factor-1 and 2; bHLH, basic helix-loop-helix.

Correspondence:

Martín G. Martín, M.D., M.P.P.

Associate Professor of Pediatrics

UCLA School of Medicine

Department of Pediatrics

Division of Gastroenterology and Nutrition

10833 Le Conte Ave

12-383 MDCC

Los Angeles, CA 90095

310 794-5532 (tel)

310 206-0203 (fax)

mmartin@mednet.ucla.edu 


\section{ABSTRACT}

The polymeric Ig receptor (plgR) is a critical component of the mucosal immune system and is expressed in largest amounts in the small intestine. In this study, we describe the initial characterization of the core promoter region of this gene. Expression of chimeric promoter-reporter constructs was supported in Caco2 and HT-29 cells, and DNase I footprint analysis revealed a large protein complex within the core promoter region. Site directed mutagenesis experiments determined that elements within this region serve to either augment or repress basal activity of the human plgR promoter. Band shift assays of overlapping oligonucleotides within the core promoter identified eight distinct complexes; the abundance of most complexes was enhanced in post-confluent cells. In summary, we report the characterization of the human plgR promoter and the essential role that eight different nuclear complexes have in controlling basal expression of this gene in Caco2 cells. 


\section{INTRODUCTION}

The human polymeric Ig receptor (plgR) is a critical component of the mucosal humoral immune system as it transports immunoglobulins across the epithelial barrier (1). After synthesis, plgR is targeted to the basolateral membrane where it binds non-covalently with high affinity to both $\lg A$ dimer $(\mathrm{plg} A)$ and pentameric $\lg M(\mathrm{plg} M)(19,28)$. The immunoglobulin-receptor complex then translocates to the apical surface where it is cleaved by an unidentified protease. A portion of plgR called secretory component (SC) remains attached to the immunoglobulin and has been shown to protect $\lg \mathrm{A}$ and $\lg \mathrm{M}$ from degradation by proteolytic enzymes.

The expression of plgR mRNA is tissue and age-specific, and is also regulated by several cytokines, hormones and growth factors (20). During the suckling phase of rodent development, intestinal plgR expression is nearly undetectable; however, after weaning levels of it increases more than 20-fold (16). Polymeric Ig receptor protein and mRNA is highly expressed in the epithelial cells of the small and large intestine, and to a lesser extent in the liver, kidney, lung, salivary gland, mammary glands and endometrium (20). In human and rodent intestine, polymeric Ig receptor expression is most abundant in the less well differentiated epithelial cells that reside in the crypt, when compared to the more mature cells of the villous $(2,3,31)$.

Nuclear run-on assays demonstrated that interferon- $\gamma$ (IFN- $\gamma$ ), tumor necrosis factor- $\alpha$ (TNF- $\alpha$ ) and interleukin-4 (IL-4), augment plgR mRNA expression at the level of transcription, and the mechanism of how these cytokines regulate $p l g R$ transcription has recently been elucidated $(18,24)$. An interferon response element (ISRE) located on exon 1 of the human gene was identified as the site that confers IFN- $\gamma$-induced expression via the intermediate synthesis of interferon response factor-1 (IRF-1) (25). The human promoter also contains a 
nuclear factor- $\kappa \beta$ site that directs tumor necrosis factor- $\alpha$-induced expression, and a STAT site located in intron 1 that controls interleukin-4-induced transactivation $(27,29)$. An androgen response unit was also identified in the human promoter (31), while an active glucocorticoid response element was identified in the murine gene (13).

The basal expression of the immediate promoter region of the human $p l g R$ gene was recently examined (11). Investigators identified that a putative E-box located between nucleotides -65 to -70 relative to the start of transcription activated basal expression in intestinal HT-29, AGS and Calu-3 cells; however, the identity of the transcription factor(s) that interacted with the element were not elucidated. An inverted repeat sequence (IRS) located immediately downstream of the E-box (-52 to -65$)$ was determined to bind to an unidentified nuclear factor; however, when the IRS site was mutated, basal promoter activity was unaltered (11). Transcriptional activity of nested deletion clones also suggested that the region between -83 and -372 was transcriptionally active; however, these potential sites were not further evaluated in the study.

Using the murine plgR promoter we recently identified both a putative activator (-78 to $-70)$ and a repressor (-62 to -52$)$ element in the immediate promoter region in Caco2 human intestinal cells (16). Mobility shift assays indicated the presence of an E-box at positions -75 and -70 , and over-expression and supershift assays suggested that the basic helix-loop-helix (bHLH) protein upstream stimulatory factor-1 and 2 (USF1 and 2) up-regulated basal promoter activity (16). The murine promoter also contains an IRS site, and clones containing mutations in the region that overlapped with the IRS site (-62 to -52$)$ identified evidence of repressor activity. The nuclear protein(s) responsible for the repressor activity was not identified by band shift assays. 
To further characterize the mechanism of how the human $p l g R$ gene is regulated, we focused on defining the elements that control its basal level of expression. Deletion and sitedirected mutations of various elements within the core promoter were transiently transfected into human intestinal (Caco2, HT-29) cells lines in order to determine the elements that are required for full promoter activity. DNase I footprints and DNA binding assays were used in combination to further define the critical elements that controls the gene's basal expression.

\section{EXPERIMENTAL PROCEDURES;}

DNA Cloning and substitution mutagenesis. Four sense, -600/-579 (5'-gcaatctTACGA CAGCCACTCCTGCCACC), -234/-212 (5'-gcaatctAAGCGACAGAAGAGCATCTT), -210/-181 (5'-gcaatctCGCTTGACATTCTGTCCCTCATCCTGAAGC), -119/-108 (5'-gcaatctCCAGCCA GGAAGGCCAAAAT) and an antisense +55/+76 (5'-ataagcttCAGTTGGTAACCCCTGCCTC TC) oligonucleotides were developed to PCR amplify various size products from human genomic DNA (Fig. 3) (11). The fragments were digested with Hind III/BgI II (restriction site indicated in lowercase lettering), and subcloned into the $\mathrm{pGL}_{3}$-enhancer luciferase reporter vector (Promega), as previously described (16). Clones $h p l g R^{-600 /+76} / E-L u c, h p l g R^{-234 /+76} / E-$ Luc, $h p l g R^{-210 /+76 / E-L u c, ~ a n d ~} h p / g R^{-119 /+76} /$ E-Luc were sequenced to define their size and authenticity.

To determine which elements in the minimal promoter are critical to maintain the gene's basal level of expression, a series of clones containing 10 base pair mutations were produced by standard scanning mutagenesis, and the location of each mutation is shown in Figure 3 (17). Various mutagenizing oligonucleotides were designed in which the transversion mutations $(A<->C, G<->T)$ were introduced in the central 10-bp's and used to perform PCR with the antisense $(+55 /+76)$ oligonucleotide (Table). The PCR products were gel purified and used as megaoligonucleotides (antisense) with the upstream sense -210/- 
181 oligonucleotide for the second PCR reaction to generate clones with 10-bp mutations. The full length fragments were cut with Bg/ll/HindllI, gel purified and subcloned into the pGL3-E vector. All clones were sequenced to verify the presence of only the desired mutation.

Identification of putative DNA cis-elements. The TRANSFAC database developed at GBF-Braunschweig, Germany was used to identify the putative DNA cis-elements in the upstream region of the human plgR gene (10).

Cell culture, transfection and transfection procedure. The human intestinal (Caco2) and hamster $\mathrm{CHO}$ cells were maintained and transfected by calcium phosphate method as previously described (16). HT-29 cells were obtained from American Type Culture Collection (ATCC) and were maintained in DMEM with $20 \%$ fetal bovine serum, $200 \mathrm{U} / \mathrm{ml}$ of penicillin and $200 \mu \mathrm{l} / \mathrm{ml}$ streptomycin at $37^{\circ} \mathrm{C}$ in $5 \% \mathrm{CO}_{2}$, and were switched to $\mathrm{L}-15$ media for 48 hours prior to transfecting. Transient transfections were done using $1 \mathrm{pmol} / \mathrm{well}$ of all the luciferase expressing constructs, and $0.5 \mu \mathrm{g}$ per well of the $\mathrm{pCMV}-\beta$-galactosidase vector was transfected as a control for transfection efficiency and cell number. For comparison of clones containing specific mutations, transfection efficiency was controlled for with the use of renilla luciferase, a component of Promega's Dual Luciferase System. Co-transfection of various concentrations of several USF expression vectors was performed as previously reported. All samples were rinsed twice and processed 48 hours after transfection. Both luciferase and $\beta$ galactosidase were measured as previously described (12). Transfection of HT-29 cells was done using electroporation with the RF Module (Biorad). Each pulse had $10 \mu \mathrm{g}$ of luciferase construct and $1 \mu \mathrm{g}$ of either pCMV- $\beta$-galactosidase or renilla vector for $4 \times 10^{6}$ cells. This mixture was then pulsed at $0 \%$ modulation, $0.2 \mathrm{kV}, 50 \mathrm{~Hz}$, for $2 \mathrm{msec}$, with 1 -second intervals for 5 bursts. The volume of the DNA-cell mixture was $100 \mu$ l. This mixture was immediately 
transferred into L-15 media with serum using a $1 \mathrm{ml}$ syringe and disbursed over six well plates. The plated cells were allowed to incubate in the humidifier at $37^{\circ} \mathrm{C}$ and $5 \% \mathrm{CO}_{2}$ for 24 hours.

\section{Electrophoretic mobility shift assays (EMSA) and preparation of nuclear extract.} Nuclear extracts were obtained from Caco2 cells either 2 or 10 days after seeding by standard methods (7). Cells seeded for 2 days were subconfluent, while those seeded for 10 days were confluent for approximately 7 days. EMSA was performed as outlined previously using probes $A$ to $G$ as outlined in Figure 3 (16). Briefly, various double-stranded oligonucleotides (shown in Fig. 3) containing a GATC 5'-overhang were labeled with the use of Klenow fragment and $\left[\alpha-\mathrm{P}^{32}\right]$ dCTP $(3,000 \mathrm{Ci} / \mathrm{mol})$. Approximately $2-5 \times 10^{4} \mathrm{cpm}$ of probe and 2.5-5 $\mu \mathrm{g}$ nuclear extracts were used for each reaction. Standard competition studies were run using excess unlabeled oligonucleotide duplexes. To identify the precise outer limits of the cis-element, competition studies were performed using a series of oligonucleotides that were the same length as that of the wild-type oligonucleotides and included 5 to 3 -bp transversion mutations as specified within each figure (precise oligonucleotides not shown). Antiserum against USF1 \& 2, C/EBP- $\alpha, \beta, \gamma$, IRF-1 and CREB were all purchased from Santa Cruz Biotechnology and were used to perform supershift studies.

DNase I footprinting. To define the regions of DNA-proteins interactions, DNase I footprint analysis was performed according to established methods in our laboratory (16). The hplgR $-600 /+22 / E-L u c$ vector was cut with HindllI, kinased with $\left[\gamma-P^{32}\right]$ dATP $(6,000 \mathrm{Ci} / \mathrm{mol})$ and then cut with Bg/ll. Samples were electrophoresed on a 5\% polyacrylamide gel, purified, and diluted to $6,000 \mathrm{cpm} / \mu \mathrm{l}$. All footprints were performed with nuclear extracts isolated from Caco2 cell, and dialyzed at a final concentration of $0.1 \mathrm{M} \mathrm{KCl}$. Approximately $6,000 \mathrm{cpm}$ of 
probe were mixed with $6 \mu \mathrm{g}$ of either nuclear extracts or bovine serum albumin (BSA). Serial dilution of $D$ Nase I was added to $D$ Nase reaction buffer $\left(40 \mathrm{mM} \mathrm{CaCl}_{2}, 10 \mathrm{mM} \mathrm{HEPES}, \mathrm{pH}\right.$ 7.9, $10 \%$ glycerol, $0.1 \mathrm{mM}$ EDTA, $0.05 \mathrm{mM} \mathrm{KCl}, 28 \mathrm{mM}$ 2- $\beta$-mercaptoethanol, and $0.1 \mathrm{mM}$ of BSA). Digestion with DNase I occurred for 1 minute at $25^{\circ} \mathrm{C}$, and was then terminated with stop solution (10 mM EDTA, $0.2 \%$ SDS, $40 \mathrm{mM}$ sodium acetate, and $50 \mu \mathrm{g} / \mathrm{ml}$ yeast tRNA). Samples were purified with phenol and chloroform, precipitated with ethanol and run on a 6 $\%$ polyacrylamide gel $100 \mathrm{~min}$ at $50 \mathrm{~W}$. The locations of the protein/DNA binding sites were determined by running a DNA ladder sequenced by the Maxam-Gilbert method.

\section{RESULTS}

Transient transfection of the human plgR clones into HT29, Caco2 and CHO cells identified the gene's core promoter. Four clones containing different length fragments of the $5^{\prime}$ region of the human plgR gene ( $h p / g R^{-600 /+76} / \mathrm{E}^{-L u c}, h p / g R^{-234 /+76} / \mathrm{E}-\mathrm{Luc}, h p / g R^{-210 /+76}$ /E-Luc, hplgR ${ }^{-119 /+76 / E-L u c) ~ w e r e ~ t r a n s f e c t e d ~ i n t o ~ v a r i o u s ~ c e l l ~ l i n e s ~(F i g . ~ 1) . ~ T r a n s f e c t i o n ~ o f ~}$ Caco2 and HT-29 cells with either hplgR ${ }^{-600 /+76} /$ E-Luc or $h p / g R^{-234 /+76 / E-L u c ~ r e s u l t e d ~ i n ~}$ promoter activity that was between 10 to 20 -fold higher than the promoter-less pGL3-E vector. In contrast, in $\mathrm{CHO}$ cells promoter activity was only slightly higher than what was observed with the promoter-less vector.

DNA footprint analysis of hplgR's upstream core promoter identified a large footprint with multiple hypersensitivity sites. DNase I footprint experiments of the immediate upstream region of the promoter were performed using only nuclear extracts from Caco2 cells. The region was analyzed in the sense $\left(5^{\prime} \rightarrow 3^{\prime}\right.$, Fig. $\left.2 \mathrm{~A}\right)$ and antisense $\left(3^{\prime} \rightarrow 5\right.$, Fig. $\left.2 \mathrm{~B}\right)$ directions. Footprint analysis in the sense direction identified a rather large footprint containing three hypersensitivity sites, suggesting the presence of DNA-protein interactions 
located between -135 and -46 (Fig. 2A). When this region was analyzed in the antisense direction, a slightly larger footprint was identified that extends up to 190 nucleotides upstream of the start of transcription (Fig. 2B). Overall, these data suggest that the immediate 5'upstream region of the human $p l g R$ core promoter contains a large region that is capable of binding to Caco2 nuclear extracts (Fig. 3).

EMSA and transfection of reporter clones containing substitution mutations in the immediate promoter region defines several active elements. In order to further define the critical elements in the core promoter region of the $h p / g R^{-210 /+76 / E-L u c ~ v e c t o r, ~ a ~ s e r i e s ~ o f ~}$ 20 scanning mutagenesis clones was generated (some data not shown). Each clone contained a different stretch of 10 mutated contiguous nucleotides within the 286-bp minimal promoter (from -210 to +76 ) (Fig. 3). Transfection of the majority of mutant clones in Caco2 cells had a level of activity that was similar to the non-mutated wild-type clone (data not shown). The M2 region corresponded to the TATA box (-26 to -30$)$, and the promoter activity of the M2 clone was significantly lower than the wild-type vector, indicating the important role of general transcription factors in controlling promoter activity (data not shown).

The clone contained a mutation in the M4 region, which increased promoter activity five-fold in Caco2 cells (Fig. 4B). Probe A, which spans -22 to -65 , was used to assess this region for DNA-protein complexes in the M4 region. For the sake of clarity, the EMSA performed in Figure $4 \mathrm{C}$ was with a form of probe $A(\mathrm{M} 4)$ that contains a mutation in the M4 region (-40 to -49$)$ (Fig. 4A). EMSA with the mutant oligonucleotide resulted in three specific complexes $\left(A_{1}-A_{3}\right.$, lanes 1 and 2$)$. However, when competed with the wild-type oligonucleotide (lane 3 ) only complexes $A_{2}$ and $A_{3}$ competed for binding, suggesting that the $A_{1}$ complex is unique to the M4 probe. The remaining competition studies (lanes 4-8) were consistent with the hypothesis that the mutation in the M4 region creates an actual E-box. Supershift studies using USF1 and 2 antiserum confirmed that the $A_{1}$ complex consist of 
USF1 and 2 (lanes 10-15). Overall, these data are consistent with the hypothesis that the M4 mutation creates an E-box (CACGTG) (see thin rectangle) (Fig. 4A) and therefore, the induction of promoter activity with the M4 clone (Fig. 4B) was not secondary to a loss of a repressor element, but instead the introduction of an activator. Complexes $A_{2}$ and $A_{3}$ are specific to the wild-type oligonucleotide; however, their identity and the location where they bind the $A$ probe has not been elucidated.

Clones containing mutations in the M6 and M7 region had promoter activities that are $<10 \%$ of the wild type (Fig. 5B). Probe $B(-74$ to -35$)$ is located in the region of M6 and M7 and, in the presence of nuclear extracts, forms two large prominent and specific complexes labeled $B_{1}$ and $B_{2}$, and a faster migrating complex of much lower intensity $B_{3}$ (Fig. $5 \mathrm{C}$, lanes 1-4). To determine the precise location of the DNA-protein complex, EMSA competition experiments were performed. The sequence of the most critical region of the $B$ probe is displayed in the Figure $5 \mathrm{~A}$, and the location of the nucleotides mutated in the competition experiment is shown just below by a lowercase letter bracketed by two parallel lines. Competition experiments with oligonucleotides $(\mathrm{Ba})$ containing mutations in the putative Ebox $(-71$ to -66$)$ failed to bind to the proteins that form the three complexes (lanes $5-7$ ), and supershift studies (lanes 16-21) confirmed that the complexes represent USF1 and 2 homoand heterodimers. Competition with the oligonucleotide $(B b)$ that contains a mutation within the previously described IRS region demonstrates that this region fails to form complexes (lanes 8-10). Both complexes were equally abundant in nuclear extracts isolated from preand postconfluent Caco2 cells (lanes 12-15). These data suggest that the basic helix-loophelix proteins USF1 and USF2 are equally abundant in pre- and postconfluent cells, and that they form the $B_{1}$ and $B_{2}$ complexes that activate basal expression of the immediate plgR promoter region. 
Transactivation with expression vectors containing USF1 and 2 were capable of augmenting promoter activity of the wild-type $h p l g R^{-210 /+76}$ vector in a dose-dependent manner, while the dominant negative (DN) constructs significantly diminished activity (Fig. 5D). Transfection of the USF1 and USF2 expression vectors failed to alter promoter activity of the M6 clone, indicating that the sole E-box in the promoter resides between nucleotides 71 and -66 .

The $C$ probe spans nucleotides -122 to -82 and forms three relatively small complexes $C_{1}-C_{3}$ with Caco2 nuclear extracts (Fig. $6 \mathrm{C}$ ). Competition with duplex oligonucleotides that contained specific mutations in the Cf to Ci regions (nucleotides -104 and -93) was capable of only partially binding to the three complexes (lanes 9-12) (Fig. 6A/C). Mutagenesis of the region that disrupts the upstream portion of this complex (M10) resulted in a three-fold increase in promoter activity, while mutation of the M9 region failed to influence reporter activity (Fig. 6B). While the element resembles an interferon stimulated response element, it contains several sequence polymorphisms that would interfere with its ability to interact with the interferon regulatory factor (IRF) family of proteins (14). In fact, anti-IRF1 antibodies failed to supershift the complexes (data not shown). To determine if the abundance of the $C_{1}-C_{3}$ complexes varied by the stage of Caco2 cell confluency, nuclear extracts were isolated 2 (subconfluent) and 10 (postconfluent) days after the cells were seeded on plastic plates. The complexes were significantly more abundant in nuclear extracts isolated from postconfluent rather then subconfluent cells (lanes 17-20). Since transient transfection analysis is limited to subconfluent dividing cells, the role of a transcription factor that is primarily expressed in the post-confluent state may be indiscernible by this analysis. These data were interpreted to suggest that the proteins that form complexes $C_{1}$ to $C_{3}$ have a distinct repressor role and are more abundant in quiescent compared to proliferating Caco2 cells. 
Probe $D$ is composed of nucleotides -137 to -107 , and by EMSA forms two vastly different size complexes (Fig. 7C, lane 1-5). In competition experiments, the upper complex $\left(D_{1}\right)$ failed to be competed by duplex oligonucleotides containing mutations at positions $D c$, $D d, D f, D g$, and $D h$ (lanes 8, 9, 11-13, Fig. 7A). These data suggest that the protein complex that forms the $D_{1}$ complex specifically interacts with DNA located between nucleotides -130 to -114. The $D, G$ and $G^{\prime}$ probes specifically competed for formation of the nuclear extract forming the $D_{2}$ complex in these assays (lanes 17-20). These data indicate that the $D_{2}$ complex is identical to the complex formed with the $G$ probe that is located between nucleotides -174 and -169 (Fig. 3, data not shown). A mutation in the M12 region disrupts both complexes $\left(D_{1}\right.$ and $\left.D_{2}\right)$, and leads to a three-fold increase in promoter activity (Fig. 7B). However, mutation M11 and M13 selectively prevents the formation of the $D_{1}$ complex and fail to influence basal activity (Fig. 7B). The $D_{1}$ and $D_{2}$ complexes were most abundant in postconfluent Caco2 nuclear extracts, and were barely detectible in rapidly dividing subconfluent cells (lanes 25-28). The cis-acting element (ATGGAG) that binds to the $D_{2}$ complex appears to be unique, since it does not resemble any previously identified transcription factor binding site (10). In contrast, the upper complex $\left(D_{1}\right)$ is formed by a transcription factor that binds an element that resembles a putative binding site (nucleotides from -122 to -133 ) for C/EBP transcription factors (21). However, the protein responsible for forming the slower migrating $D_{1}$ complex clearly interacts with nucleotides as far downstream as -114 , making it unlikely that a member of the bZIP family of proteins form the complex. Moreover, supershift studies with anti-C/EBP- $\alpha, \beta, \gamma$ antisera failed to shift the $D_{1}$ complex (data not shown). Taken together, these data suggest that the novel $D_{1}$ and $D_{2}$ complexes are formed by composite factors that are present in highest abundance in quiescent cells and repress basal promoter activity of the human $p / g R$ promoter. 
The $E$ probe was located just upstream of probe $D$ between nucleotides -150 to -132 , and EMSA analysis with this probe results in two intermediate size complexes ( $E_{1}$ and $E_{2}$, Fig. 8C). Competition with oligonucleotides containing specific mutations revealed that only the $E b$, to $E d$ oligonucleotides failed to compete for the two specific complexes, suggesting that the nuclear extract interacts with nucleotides located between -144 and -136 (Fig. 8C, lanes 13-15). While the abundance of the $E_{1}$ and $E_{2}$ complex was barely detectable in nuclear extracts isolated from the dividing, subconfluent cells, levels were significantly higher in postconfluent cells (lanes 18-21). The relative absence of these complexes in nuclear extracts isolated from dividing Caco2 cells may explain why site-directed mutagenesis of this region (M13 and M14) failed to alter basal promoter activity (Fig. 8B). The protein(s) that forms these complexes appears to weakly resemble a cAMP-responsive element (CRE) (10); however, anti-CRE binding protein (CREB) antibodies fail to supershift the complex, indicating that a transcription factor other then CREB forms the complex (data not shown).

Probe $F$ is a duplex probe composed of nucleotides between -171 to -142 and EMSA with Caco2 nuclear extracts formed both large and small complexes $\left(F_{1}\right.$ and $\left.F_{2}\right)$ that were competed by an excess of unlabeled $F$ probe (lanes 2 and 3, Fig. 9C), but not by an unrelated double stranded oligonucleotide (lane 9). Competition with unlabeled oligonucleotides that contained mutations in the Fa to Fd region (lanes 4-7) failed to compete for the $F_{1}$ complex, indicating the location of the nucleotides $(-165$ to -154$)$ that interact with the nuclear extracts. Both complexes were slightly more abundant in nuclear extracts isolated from postconfluent Caco2 cells (lanes 14-17, Fig. 9C). Site-directed mutagenesis of this element results in a barely detectable $40 \%$ increase in promoter activity (Fig. 9B). While this element appears to be unique, it weakly resembles cis-elements recognized by two homeobox proteins ( $\mathrm{Cdx}-2$ and Nkx-2.5); however, the identities of the proteins that bind to these sites have not yet been determined. 


\section{DISCUSSION}

In this study we analyzed the 5'-flanking region of the human plgR gene using transfection studies, DNase I footprint analysis and DNA binding assays. Transfection into both intestinal (Caco2/HT-29) and the non-expressing $\mathrm{CHO}$ cell lines with the human plgR ${ }^{-}$ ${ }^{210 /+76}$ promoter regions reveals the specificity of the promoters activity (Fig. 1). DNase I footprint analysis confirmed the presence of multiple footprints and hypersensitivity sites located between nucleotides -46 to -190 relative to the start of transcription and within the gene's minimal promoter. (Fig. 2). The pattern of footprints identified in the human promoter is distinct to what we have previously reported with the murine gene (16). Regulation of $p l g R$ expression does differ between humans and rodents, since rodent and rabbit plgR is expressed in hepatocytes, while it is expressed in biliary epithelium of humans (6). Moreover, expression in the intestinal epithelium of humans occurs as early as 20 weeks of gestation, and at 3 weeks of postnatal life in rodents (20).

We employed an unbiased approach (scanning mutagenesis) to determine the regions of the core promoter that influences its activity. One drawback to such an approach is that the mutations can create an active region by introducing a cis-element. Such was the case with the M4 mutant, which increased promoter activity not by the removal of a repressor element, but instead, the introduction of an active E-box, which binds USF1/2 and augments promoter activity (Fig. 4).

Probe $B$ overlaps with both an E-box (-71/-66) and the IRS element (-65/-50), and competition studies shown in Figure 5 demonstrate that the three complexes ( $B_{1}$ to $\left.B_{3}\right)$ interact with the putative E-box. In a recent analysis of the human plgR promoter, Johansen et al. demonstrated the importance of the E-box in conferring basal expression in gastric AGS epithelial cells (11). Similarity, we demonstrated that the E-box located in a similar region of 
the murine gene was also essential for driving basal promoter activity in Caco2 cells (16). The role of the leucine zipper protein (bHLH/LZ) USF1 and 2 in augmenting basal expression of the murine plgR gene was confirmed by supershift and over-expression assays using both wild-type and their corresponding dominant negative vectors. Similar studies were performed with the human core promoter, and confirm the role of USF1 and USF2 in transactivation the basal expression of the plgR gene (Fig. 5D).

Transfection of a clone (M5) that disrupts the IRS site (-65/-50) failed to significantly alter transcriptional activity (Fig. 3 and data not shown). A similar mutation in the murine promoter results in a six-fold elevation of promoter activity compared to that of the wild-type vector (16). Three base pair mutations covering the entire IRS element (including an additional seven-nucleotides downstream) augmented basal expression in Caco2 cells (16, and unpublished data). In the human promoter, however, transfection of the M5 clone only increased activity by $50 \%$ (data not shown). Despite developing several overlapping oligonucleotides, we have not been able to consistently detect a specific complex that bind to the IRS region (data not shown). In contrast, Johansen et al. were capable of identifying a complex that they attributed to binding at the IRS; however, mutation of the site failed to alter transcriptional activity in AGS cells and did not disrupt complex formation (11). The authors speculated that their failure to alter promoter activity might have occurred because they introduced transition mutations, which may have been insufficient to completely disrupt binding or alter transcriptional activity. In the current study, we altered the IRS by substituting with transversion mutations, yet these mutations still failed to change transcriptional activity, raising the possibility that this site is only transcriptionally active in the murine promoter (16).

The $C$ complexes bind to a DNA element that is an insertion in the human promoter and is not present in the murine gene (Fig. 3). Mutagenesis of this region suggests that the proteins that form the $C_{1}$ to $C_{3}$ complexes have a role in repressing basal promoter activity 
(Fig. 6). The EMSA competition studies do indicate that mutations of nucleotides -107 to -99 (region $e$ to $g$ ) most substantially altered the formation of the $C_{3}$ complex, and these data are most consistent with the transfection data that demonstrates that the promoter activity of the M10 clone was more significantly altered when compared to M9. Since mutations located in M9 should disrupt binding of the $\mathrm{C} 1$ and $\mathrm{C} 2$ complexes, the transfection data indicates that these two complexes may not alter promoter activity. While the transfection data clearly suggests the alterations in the upstream portion (M10) of the element most dramatically influences promoter activity, the three $C$ complexes are not as abundant in nuclear extracts of subconfluent Caco2 cells. Transient transfection studies performed in this study occurred in subconfluent-dividing cells. Therefore, it is possible that the magnitude of the $C$ complexes influence on plgR promoter activity is more significant in differentiated, non-dividing cells than can be measured by standard transfection assays.

Kaetzel previously studied this region of the human plgR promoter and determined that the complexes that interacted in this area failed to be supershifted by antiserum to IRF-1, IRF-2, ISGF3- $\gamma$ and STAT1 (25). The influence of this element on basal promoter expression, however, was not previously evaluated and the single complex detected previously does not resemble the complex detected in our analysis.

Through sequence homology, Kaetzel also identified another element that resembles an ISRE located between nucleotides -128 and -138 (25). This putative element spans the complexes identified with probe $D$ and $E$. The previous analysis of this region may have not detected either complexes $D_{1}-D_{2}$ or $E_{1}-E_{2}$ because the investigators failed to use a probe of sufficient length, and because the protein responsible for the $D_{1}$ and $D_{2}$ complex is found in low concentrations in HT-29 nuclear extracts (data not shown). Nevertheless, this element is 
clearly not binding members of the C/EBP family of proteins, since antiserum towards $\alpha, \beta$, and $\gamma$ all fail to supershift the complex (21).

The faster migrating complex $\left(D_{2}\right)$ formed with the $D$ probe interacts with the ATGGAG element located from -125 to -120 and does not resemble any previously described ciselement (Fig. 7A). An identical element located from -173 to -168 was identified with the $G$ probe, which itself was capable of competing for binding of the nuclear extract with the $D$ probe (Fig. 7C, lane 20). In Figure 7, competition with an oligonucleotide containing a transversion mutation at location $D f$ could only partially compete for binding to the complex (Fig. 7, lane 11). Similar results were obtained with probe G; however, when transition mutations were substituted (GAG to AGA) the probe failed to compete for the complex (data not shown). While mutations (M11 and M13) that selectively prevent the formation of the upper complex with probe's $D$ only marginally increase basal expression, clone M12 that results in a disruption of both complexes increases promoter activity more than 3-fold (Fig. 7A). Therefore, the significant up-regulation of basal expression that occurs with the clones that contain mutations that disrupt both complexes, suggests that the protein(s) that binds to these elements function in a cooperative manner to repress promoter activity. Since the $D$ complexes are most abundant in post-confluent cells, their influence in controlling plgR expression may be more dramatic in quiescent cells.

The most abundant complex that we identified in this study was the $E$ complex, which also formed a very specific interaction with the identified cis-element (Fig. 8C). However, transfection studies failed to identify a role of this element in controlling $p / g R$ expression (Fig. 8A). Nuclear extracts from subconfluent cells contained only a marginal amount of the complex, and may have made it difficult to discern whether this complex has a positive or negative influence on plgR promoter activity in the non-dividing state. Of all the complexes 
identified in this study, only USF1 and 2 that bind to the $\mathrm{E}$ box and augment promoter activity are expressed in similar concentrations in pre and postconfluent cells (Fig. 5C, lanes 12-15). Interestingly, plgR expression in the intestine is most abundant in the less well-differentiated cells of the crypt, and is decreased in the mature cells of the villous $(2,3,31)$. Several investigators have argued that subconfluent in vitro cells resemble cells in the intestinal crypt, while postconfluent cells are a more appropriate model for the differentiated and quiescent cells that populate the villous $(26,5)$. Since complexes $C$ and $D$ appear to have an inhibitory effect on $p l g R$ promoter activity, their role in the intestinal villous may be to diminish $p l g R$ expression in vivo.

Site-directed mutagenesis of the element that forms the $F$ complexes (TCCCAAGTAACA) results in a marginal $40 \%$ enhancement of basal promoter activity (Fig. 9B). While this element appears to be unique, it resembles cis-elements recognized by two homeobox containing proteins $\mathrm{Cdx}-2$ and $\mathrm{Nkx}-2.5(9,22)$. While expression of Nkx-2.5 is limited to cardiac mesoderm and is essential for cardiac development, its counterpart, Nkx2.3, is also expressed in gut mesenchyme during early development (22). Targeted disruption of the Nkx-2.3 gene results in early postnatal death and a marked reduction in the proliferation of epithelial cells of the intestinal villous (23). However, the element identified with the $F$ probe does not have a well-preserved $\mathrm{Cdx}-2$ core element (ATTTACA), which is believed to be critical for its function (9). Nevertheless, Cdx-2 plays a critical role in controlling basal expression of several genes that are developmentally regulated in the small intestine, including sucrase-isomaltase, lactase-phlorizin hydrolase and apolipoprotein $B(9)$. While the murine plgR gene is also developmentally regulated in a similar pattern to both sucrase-isomaltase and the apolipoprotein B genes, with the exception of the E-box, the murine promoter does not appear to contain any of the active elements identified in the human gene (11). The precise identification of the various protein complexes that bind to 
these distinct regions in the human promoter and their role in controlling basal and stimulated activity awaits further analysis.

\section{ACKNOWLEDGEMENT}

We would like to thank Drs. Michèle Sawadogo and Howard Towle for providing the USF1, USF2, USF1DN and USF2DN expression clones.

\section{LEGEND}

Table: Oligonucleotides used for mutagenesis. The oligonucleotides used to perform sitedirected mutagenesis of the human plgR $-210 /+76$ clone are displayed. The mutated nucleotides are shown in bold and italicized lowercase letters, and their location relative to the start of transcription are shown on the left.

Figure 1: Transient transfection of various plgR 5'-upstream promoter deletion clones. As described in the methods section, $\mathrm{CacO} 2$, and $\mathrm{CHO}$ cells were transfected by standard calcium phosphate method, while HT-29 cells were transfected by electroporation. Chimeric promoter-reporter constructs were precipitate with 10 -fold less $\beta$-galactosidase vector driven by a CMV-promoter. After processing 48 hours later, relative light units (RLU) and $\beta$ galactosidase-activity were measured. Data is shown as fold-elevation of the empty pGL3enhancer vector. Values are means \pm SD of sextuplet data from two experiments.

Figure 2: Bi-directional $D N a s e$ I footprint analysis of $h p l g R$ gene. Footprint analysis was performed with nuclear extracts isolated from Caco2 cells. DNA was labeled in either the sense $\left(\boldsymbol{A}: 5^{\prime}\right.$ to $\left.3^{\prime}\right)$ or antisense $\left(\boldsymbol{B}: 3^{\prime}\right.$ to $\left.5^{\prime}\right)$ orientation, in the presence of either bovine serum albumin (- ; lanes 1-2, 5-6) or with Caco2 (+ ; lanes 3-4, 7-8) nuclear extracts. DNase I was added at two different dilutions and indicated by a triangle. The dark-shaded rectangle to the 
right of each image depicts the location of the footprint and the asterisk $\left(^{*}\right)$ shows the location of the hypersensitivity sites. The Maxam-Gilbert sequencing ladder is shown adjacent to each panel for comparison.

Figure 3: The 5'-flanking sequence of human, rat, and murine $p / g R$ promoters are shown for comparison. Nucleotides conserved between the human (h) (11), rat (r) (8), murine $(m)(15)$ (indicated on the left) genes are highlighted by a gray shaded rectangle. Nucleotides are numbered relative to the start of transcription (indicated on the right), and the location of the mutation in each clone are labeled M1 to M20, with the boundaries of each mutation identified by short vertical lines. The location of each double-stranded oligonucleotides used for band-shift assays are shown as a horizontal line below its corresponding sequence and are labeled "A to G Probe". A clear rectangular box located on the human stretch of DNA shows the location of each DNA-protein complex identified in this study. The relative locations of the footprints identified in Figure 2 are displayed as a gray shaded rectangle and the hypersensitivity sites are shown as an asterisk $\left(^{*}\right)$. The TATA box, E-box and IRS elements are also highlighted.

Figure 4: Transient transfection and EMSA of the Probe $A$ region. $A$ The probe used for EMSA was M4, which contains the M4 mutation and spans -22 to -65 . The thin-lined rectangle highlights the location of the E-box (CACGTG) that was introduced by the M4 mutation (thick-lined rectangle on the right). The locations of the nucleotides that are altered by the M4 mutation are indicated above the large rectangle. B. Caco2 cells were transiently transfected with either the wild-type clone $\left(\mathrm{hPR}^{-210 /+76}\right)$ or $\mathrm{M} 4$ clone and luciferase activity measured 48 hours later. Data is displayed as fold elevation over hPR $-210 /+76$ wild type. C. Competition was performed with several duplex oligonucleotides that were either wild type or mutants (lanes 2-8). Specifically, the Ba oligonucleotide corresponds to the $B$ probe (-74 to - 
$35)$, and contains a mutation in the E-box $(-71$ to -66$)$. In contrast, the $B b$ oligonucleotide contains a mutation in the putative IRS element (-61 to -53). The A' oligonucleotide scans 79 to -60 , while the $A$ " oligonucleotide includes bases -59 to -29 . Antiserum to USF1/2, E47 or non-reactive serum was used to perform supershift experiments (lanes 11-15).

Figure 5: Transient transfection and EMSA of the Probe $B$ region. $A$. Nucleotides that are essential for binding nuclear protein are depicted within the rectangular box with the outer nucleotides numbered. The location of the M6 and M7 mutations are shown above the rectangle, while those in the oligonucleotides used in the EMSA are displayed below the rectangle. All oligonucleotides were annealed to an antisense counterpart (sequence not shown). B. Caco2 cells were transiently transfected with clones M5, M6 or wild type and luciferase activity was measured 48 hours later. C. Crude Caco2 nuclear extracts and probe $A$ were used for lanes 1-11. Competition experiments were performed with 50, 100 and 250fold excess (indicated by triangle) of either cold wild-type probe $B$ (lanes 2-4), or mutant clones $\mathrm{Ba}$ (lanes 5-7), Bb (lanes 8-10) or unrelated $U$, lane 11). The arrows indicate the location of the three specific complexes $\left(B_{1}\right.$ to $\left.B_{3}\right)$. In lanes 12 to 15 , nuclear extracts were isolated from Caco2 cells either 2 or 10 days after seeding. Supershift studies were performed with either or both anti-USF1 or USF2 antiserum (lanes 17-20) or nonreactive serum (lane 21). D. Either the wild-type clone $\left(\mathrm{hPR}^{-210 /+76}\right)$ or mutant $\mathrm{M} 6$ clones were cotransfected with various concentrations of the USF1, USF2, USF1 dominant negative (USF1 DN) and USF-2 dominant negative (USF2 DN) expression vectors (see insert). Luciferase activity was measured 48 hours later with data shown relative to the promoter activity of the wild-type vector transfected in the absence of expression vectors.

Figure 6: Transient transfection and EMSA of the Probe $\boldsymbol{C}$ region. $\boldsymbol{A}$. The location of the nucleotides mutated in each oligonucleotide is shown as a lower-case letter surrounded by a vertical line, while those of the M10 and M9 clone are shown above the rectangle. 
Promoter activity was assessed in Caco2 cells by transiently transfecting clones M9, M10 or wild-type and measuring luciferase activity. C. Competition with 100-fold excess of duplex oligonucleotides of either probes $C$ (lane 2), $D$ (lane 3 ) or that contained mutations in various regions ( $\mathrm{Ca}-\mathrm{Cl})$ (lane 4 and 15). Competition with unrelated $(U)$ duplex oligonucleotides is shown in lane 16. In lanes 17 to 20 , nuclear extracts were isolated from Caco2 cells either 2 or 10 days after seeding. The arrowheads indicate the location of the three complexes.

Figure 7: Transient transfection and EMSA of the Probe $\boldsymbol{D}$ region. $\boldsymbol{A}$ The region of DNA responsible for forming the two complexes is contained within the two rectangles and the outer limits of the complexes are numbered, while those of the M11 to M13 clones are shown above the rectangle. B. Caco2 cells were transiently transfected with clones M11-13 or wildtype clones and luciferase activity was measured 2 days later. C. Caco2 extracts identified two specific complexes indicate by the arrowheads $\left(D_{1}\right.$ and $D_{2}$, lanes 1-5). Competition with unlabeled oligonucleotides containing mutations $(D a-D j)$ that are specified below the sequence that is surrounded by a rectangle. In lanes 25 to 28 , nuclear extracts were isolated from Caco2 cells either 2 or 10 days after seeding.

Figure 8: Transient transfection and EMSA of the Probe $E$ region. $A$. The region of DNA responsible for forming the two complexes is contained within the rectangle and the outer limits of the complexes are numbered, while those of the M13 and M14 clones are shown above the rectangle. B. Promoter activity was assessed in Caco2 cells by transiently transfecting M14, M13 or wild-type clones. C. Two specific complexes $\left(E_{1}\right.$ and $\left.E_{2}\right)$ are indicated with filled-in arrows and the location of the nucleotides responsible for a rectangular box surrounds protein interactions. Competition experiments were performed with 100 -fold excess of either wild type (lanes 2-8, 10, 11) or mutant (lanes 12-16) duplex oligonucleotides. In lanes 18 to 21 , nuclear extracts were isolated from Caco2 cells either 2 or 10 days after seeding. 
Figure 9: Transient transfection and EMSA of the Probe $\boldsymbol{F}$ region. $\boldsymbol{A}$ The region of DNA responsible for forming the two complexes is contained within the rectangle and the outer limits of the complexes are numbered, while those of the M15 and M16 clones are shown above the rectangle. B. Caco2 cells were transiently transfected with the M15, M16 and wild type clones and luciferase activity was measured 48 hours later. C. Competition mobility shift assays (100-fold excess) were performed with either wild-type probes F, G', G, E (lanes 2-3, 10-13, and 15), or mutant oligonucleotides Fa-Fe (lanes 4-8) and unrelated (U) oligonucleotide (lane 9). In lanes 14 to 15, nuclear extracts were isolated from Caco2 cells either 2 or 10 days after seeding. The arrowhead indicates the location of the complex. 


\section{REFERENCES}

1. Brandtzaeg, P. Development and basic mechanisms of human gut immunity. Nutrition Reviews 56: S5-S18, 1998.

2. Brown WR, Isobe K, Nakane PK, Pacini B. Studies on translocation of immunoglobulins across intestinal epithelium. IV. Evidence for binding of $\lg A$ and $\lg M$ to secretory component in intestinal epithelium. Gastroenterology. 73(6):1333-9, 1977.

3. Buts J.P., D.L Delacroix. Ontogenic changes in secretory component expression by villous and crypt cells of rat small intestine. Immunology. 54(1):181-7, 1985.

4. Crottet, P. and B. Corthésy. Secretory component delays the conversion of secretory IgA into antigen-binding competent $F\left(a b^{\prime}\right)_{2}$ : A possible implication for mucosal defense. Journal of Immunology 161: 5445-5453, 1998.

5. Dai, B., H. Wu , E. Holthuizen, and P. Singh. Identification of a novel cis element required for cell density- dependent down-regulation of insulin-like growth factor-2 P3 promoter activity in Caco2 cells. J.Biol.Chem. 276: 6937-6944, 2001.

6. Daniels CK. and D. L. Schmucker. Secretory component-dependent binding of immunoglobulin A in the rat, monkey and human: a comparison of intestine and liver. Hepatology. 7: 517-521, 1987.

7. Dignam, J. D., P. L. Martin, B. S. Shastry, and R. G. Roeder. Eukaryotic gene transcription with purified components. Methods Enzymology. 101: 582-598, 1983. 
8. Fodor, E., A. Feren, and A. Jones. Isolation and genomic analysis of the rat polymeric immunoglobulin receptor gene terminal domain and transcriptional control region. DNA and Cell Biology 16: 215-225, 1997.

9. Freund, J. N., C. Domon-Dell, M. Kedinger, and I. Duluc. The Cdx-1 and Cdx-2 homeobox genes in the intestine. Biochem.Cell Biol. 76: 957-969, 1998.

10. Heinemeyer, T., E. Wingender, I. Reuter, H. Hermjakob, A. E. Kel, O. V. Kel, E. V. Ignatieva, E. A. Ananko, O. A. Podkolodnaya, F. A. Kolpakov, N. L. Podkolodny, and N. A. Kolchanov. Databases on transcriptional regulation: TRANSFAC, TRRD and COMPEL. Nucleic Acids Res. 26: 362-367, 1998.

11. Johansen, F. E., B. A. Bosloven, P. Krajci, and P. Brandtzaeg. A composite DNA element in the promoter of the polymeric immunoglobulin receptor regulates its constitutive expression. Eur.J.Immunol. 28: 1161-1171, 1998.

12. Lam, J. T., M. G. Martín, E. Turk, B. A. Hirayama, N. U. Bosshard, B. Steinmann, and E. M. Wright. Missense mutations in SGLT1 cause glucose-galactose malabsorption by trafficking defects. Biochim.Biophys.Acta Mol.Basis Dis. 1453 : 297-303, 1999.

13. Li, T. W. H., J. F. Wang, J. T. Lam, E. M. Gutierrez, R. S. Solorzano-Vargus, H. V. Tsai, and M. G. Martín. Transcriptional control of the murine polymeric IgA receptor promoter by glucocorticoids . Am.J.Physiol.Gastrointest.Liver Physiol. 276: G1425-G1434, 1999. 
14. Mamane, Y., C. Heylbroeck, P. Genin, M. Algarte, M. J. Servant, C. LePage, C. DeLuca, H. Kwon, R. Lin, and J. Hiscott. Interferon regulatory factors: the next generation. Gene 237: 1-14, 1999.

15. Martin, M. G., E. M. Gutierrez, J. T. Lam, T. W. Li, and J. Wang. Genomic cloning and structural analysis of the murine polymeric receptor (plgR) gene and promoter region. Gene 201: 189-197, 1997.

16. Martín, M. G., J. F. Wang, T. W. H. Li, J. T. Lam, E. M. Gutierrez, R. S. SolorzanoVargas, and H. V. Tsai. Characterization of the 5'-flanking region of the murine polymeric Ig receptor gene. Am.J.Physiol.Gastrointest.Liver Physiol. 275: G778-G788, 1998.

17. Martín, M. G., J. F. Wang, R. S. Solorzano-Vargas, J. T. Lam, E. Turk, and E. M. Wright. Regulation of the human $\mathrm{Na}^{+}$-glucose cotransporter gene, SGLT1, by HNF-1 and Sp1 . Am.J.Physiol.Gastrointest.Liver Physiol. 278: G591-G603, 2000.

18. Nilsen, E. M., F. E. Johansen, D. Kvale, P. Krajci, and P. Brandtzaeg. Different regulatory pathways employed in cytokine-enhanced expression of secretory component and epithelial HLA class I genes. European Journal of Immunology 29: 168-179, 1999.

19. Norderhaug, I. N., F. E. Johansen, P. Krajci, and P. Brandtzaeg. Domain deletions in the human polymeric Ig receptor disclose differences between its dimeric $\lg \mathrm{A}$ and pentameric IgM interaction. Eur.J.Immunol. 29: 3401-3409, 1999. 
20. Norderhaug, I. N., F. E. Johansen, H. Schjerven, and P. Brandtzaeg. Regulation of the formation and external transport of secretory immunoglobulins. Critical Reviews in Immunology 19: 481-508, 1999.

21. Oesterreicher, T. J., L. L. Leeper, M. J. Finegold, G. J. Darlington, and S. J. Henning. Intestinal maturation in mice lacking CCAAT/enhancer-binding protein $\alpha(C / E P B \alpha)$. Biochemistry Journal 15: 1165-1171, 1998.

22. Pabst, O., A. Schneider, T. Brand, and H. H. Arnold. The mouse Nkx2-3 homeodomain gene is expressed in gut mesenchyme during pre- and postnatal mouse development. Dev.Dyn. 209: 29-35, 1997.

23. Pabst, O., R. Zweigerdt, and H. H. Arnold. Targeted disruption of the homeobox transcription factor Nkx2-3 in mice results in postnatal lethality and abnormal development of small intestine and spleen. Development 126: 2215-2225, 1999.

24. Piskurich, J. F., J. A. France, C. M. Tamer, C. A. Willmer, C. S. Kaetzel, and D. M. Kaetzel. Interferon-y Induces Polymeric Immunoglobulin Receptor mRNA in Human Intestinal Epithelial Cells by a Protein Synthesis Dependent Mechanism. Molecular Immunology 30: 413-421, 1993.

25. Piskurich, J. F., K. R. Youngman, K. M. Phillips, P. M. Hempen, M. H. Blanchard, J. A. France, and C. S. Kaetzel. Transcriptional regulation of the human polymeric immunoglobulin receptor gene by interferon-gamma. Molecular Immunology 34: 75-91, 1997. 
26. Rottman, J. N. and J. I. Gordon. Comparison of the patterns of expression of rat intestinal fatty acid binding protein/human growth hormone fusion genes in cultured intestinal epithelial cell lines and in the gut epithelium of transgenic mice. Journal of Biological Chemistry 268: 11994-12002, 1993.

27. Schjerven, H., P. Brandtzaeg, and F. E. Johansen. Mechanism of IL-4-mediated upregulation of the polymeric Ig receptor: role of STAT6 in cell type-specific delayed transcriptional response [In Process Citation]. J.Immunol. 165: 3898-3906, 2000.

28. Song, W., G. Apodaca, and K. Mostov. Transcytosis of the polymeric immunoglobulin receptor is regulated in multiple intracellular compartments. Journal of Biological Chemistry 269: 29474-29480, 1994.

29. Takenouchi-Ohkubo, N., T. Takahashi, M. Tsuchiya, J. Mestecky, Z. Moldoveanu, and I. Moro. Role of nuclear factor-kappaB in the expression by tumor necrosis factor- $\alpha$ of the human polymeric immunoglobulin receptor (p/gR) gene. Immunogenetics 51: 289-295, 2000.

30. Valnes, K., P. Brandtzaeg, K. Elgjo, and R. Stave . Specific and nonspecific humoral defense factors in the epithelium of normal and inflamed gastric mucosa. Immunohistochemical localization of immunoglobulins, secretory component, lysozyme, and lactoferrin. Gastroenterology 86: 402-412, 1984.

31. Verrijdt, G., E. Schoenmakers, P. Alen, A. Haelens, B. Peeters, W. Rombauts, and F. Claessens. Androgen specificity of a response unit upstream of the human secretory 
component gene is mediated by differential receptor binding to an essential androgen response element. Molecular Endocrinology 13: 1558-1570, 1999. 


\begin{abstract}
M1 (-19/-10) GGGAGAGTGGCCCTTTAAGAGC aacttgtgttGTCAAACACTGAGCAGAGT ; M2 (-29/-20) GCCTGTGGGAGAGTGGCCagggcctctaCCAGGTGTGGGTCAAACACT; M3 $(-39 /-30)$ GGCTGGCCACGGTGCCTGTGGtctctgttaaCTTTAAGAGCCCAGGT; M4 (-49/-40) GACCCTGGCTGGCCACGtgtaagtgttGAGAGTGGCCCTTTAAGAG ; M5 $(-59 /-50) \quad$ GTGAGAGTCACATGACCCTGtagttaacatGTGCCTGTGGGAGAGTGG ; M6 (-69/-60) CAAGGGATCTGTGAGAGTCAacgtcaaagtGCTGGCCACGGTGCCTGTGG; M7 $(-79 /-70) \quad$ GAAAGGAAAGCAAGGGATCTtgtctctgacCATGACCCTGGCTGGCCA; M8 (-89/-80) AGGCCAAAATGAAAGGAAAGacctttcgagGTGAGAGTCACATGACCCTG; M9 (-99/-90) CCAGCCAGGAAGGCCAAAATtcccttccctCAAGGGATCTGTGAGAGTCA; M10 (-109/-100) GGAGCCAGCCAGGActtaaccccgGAAAGGAAAGCAAGGGATCT; M11 (-119/-110) CCAAATGGAG aactaacttcAGGCCAAAATGAAAGGAAAG ;

M12 (-129/-120) CCCCAAGGTCAAAGGAAAaacccgttctCCAGCCAGGAAGGCCAAAATGAAA ; M13 (-137/-128) AACAGAGTCTCCCCAAGGTCcccttcccaaAAATGGAGCCAGCCAGGAAGG; M14 (-147/-138) TCCCAAGTAACAGAGTCTaaaccttgaAAAGGAAACCAAATGGAGCCAGCCA; M15 (-157/-148) GCAACGATGGAGGATTCCCAAGTccactctgagCCCCAAGGTCAAAGGA ; M16 (-167/-158) GAAGCTGCAACGATGGAGG cggaaacctgAACAGAGTCTCCCCAAGGTCAA; M17 (-177/-168) GTCCCTCATCCTGAAGCTGCAcatcgttcttATTCCCAAGTAACAGAGTCTC ; M18 (-191/-182) GCAGATCTCGCTTGACATTCTGTCCCTC cgaagtcctaTGCAACGATGGAGGATTCCCAAGT; M19 (-201/-192) GCAGATCTCGCTTGACATgagtgaaagaATCCTGAAGCTGCAACGATGGAGGATTCC ;

M20 (-211/-202) GCAGATCTataggtcacgTCTGTCCCTCATCCTGAAGCTGCAACGA;
\end{abstract}

\title{
Table
}




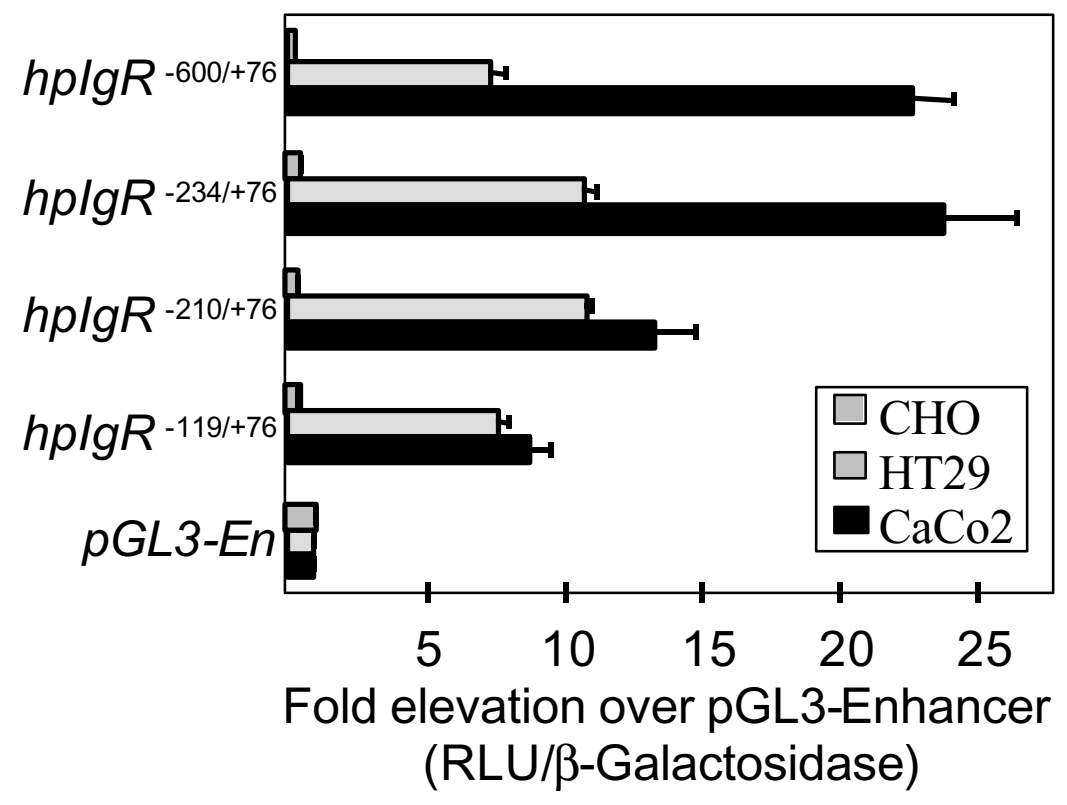

Figure 1 


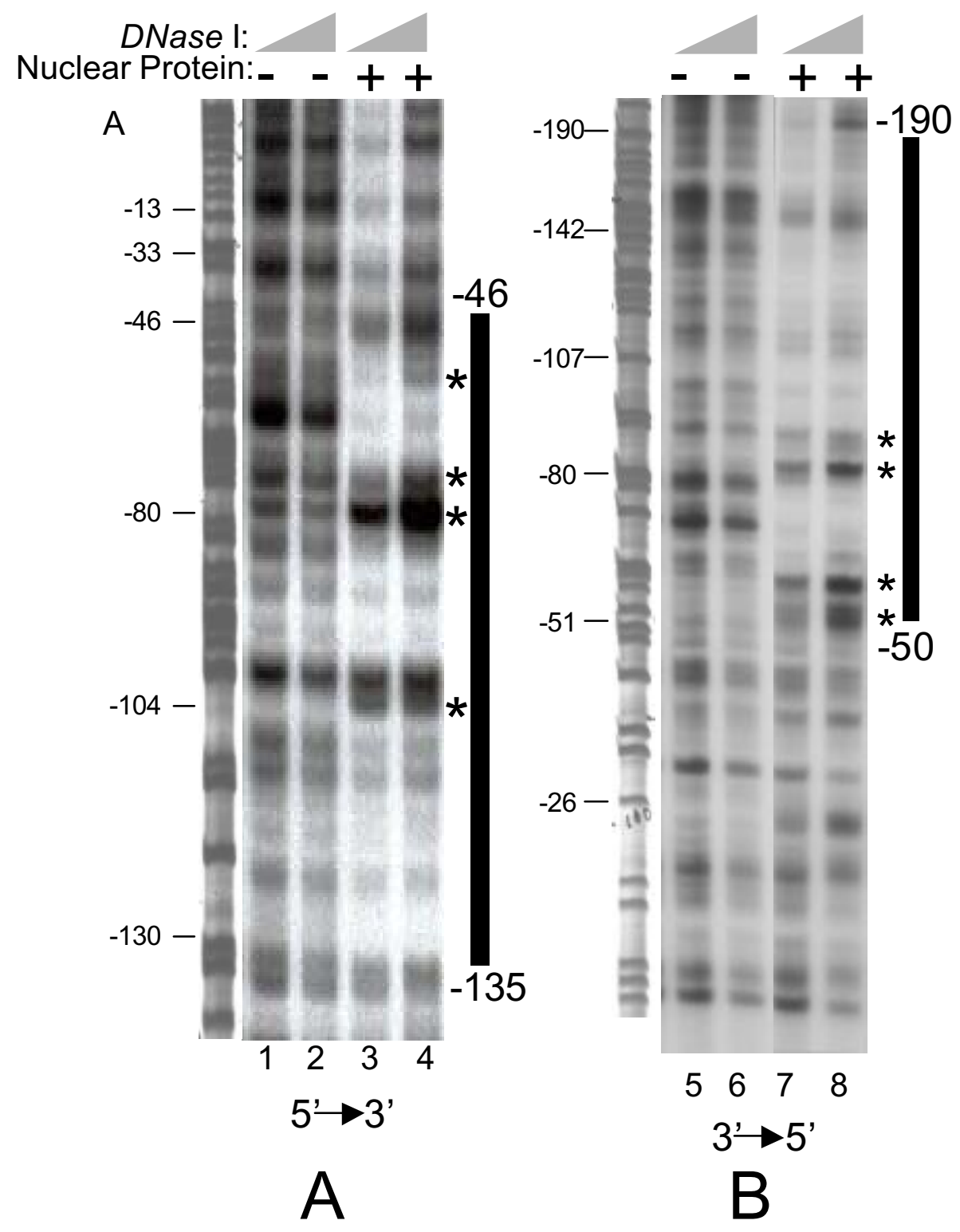

Figure 2 


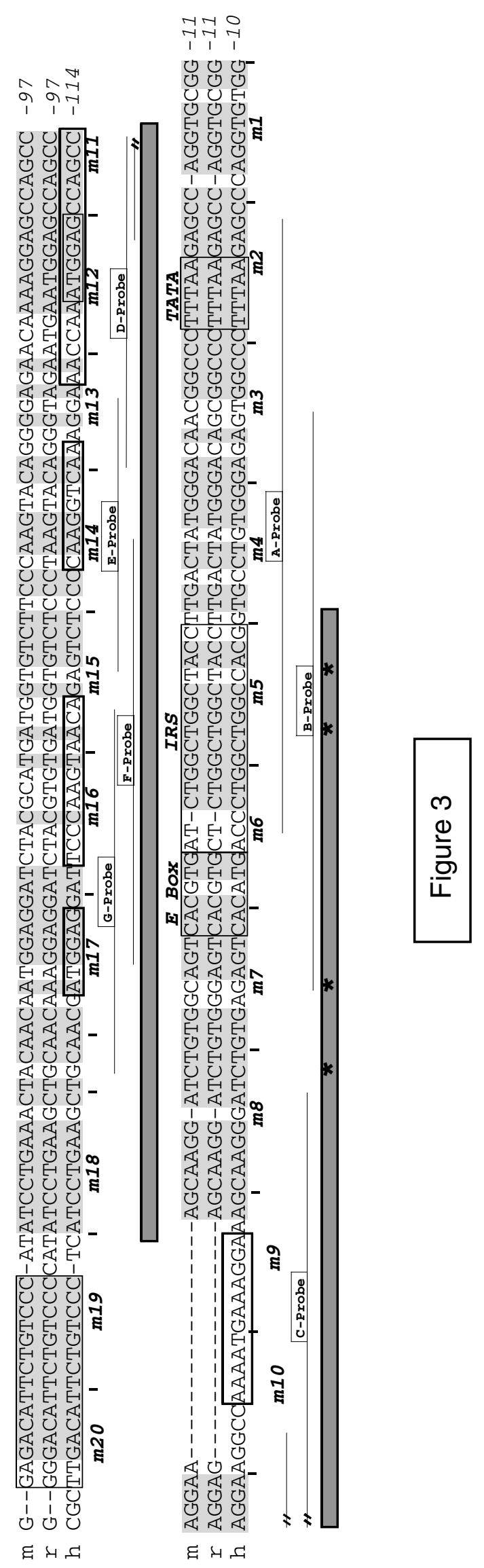




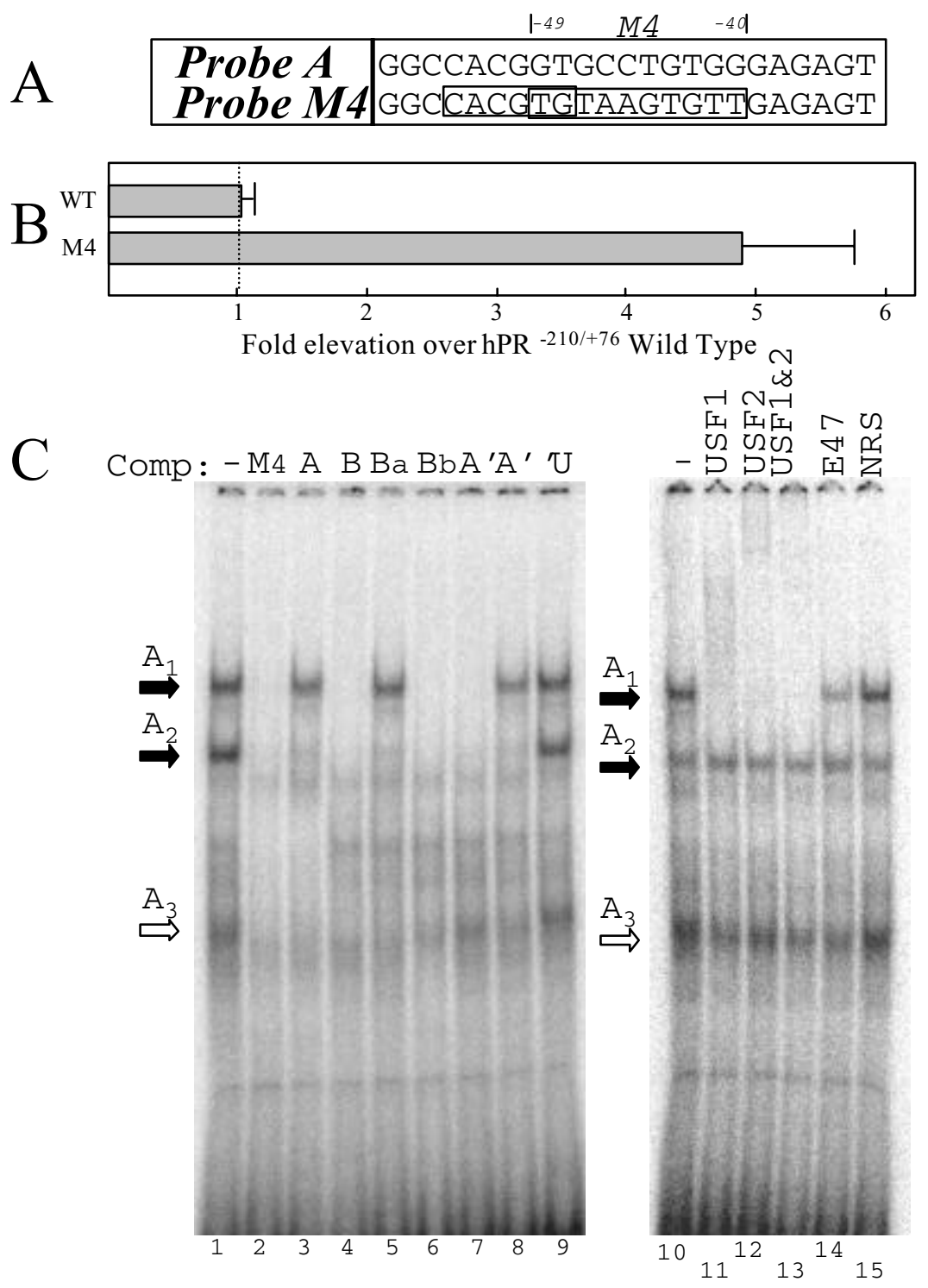

Figure 4 

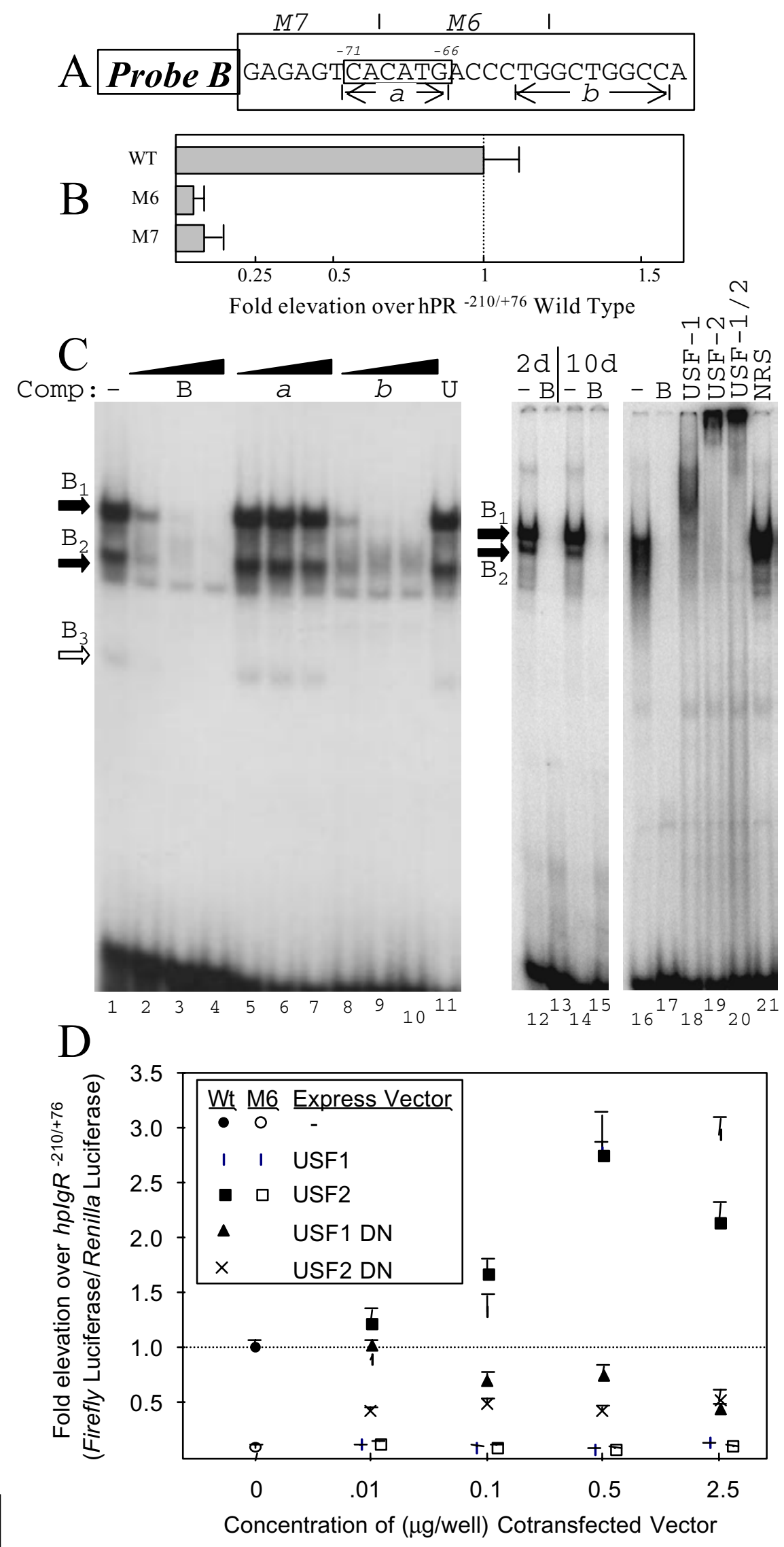

Figure 5 Concentration of ( $\mu \mathrm{g} /$ well) Cotransfected Vector 

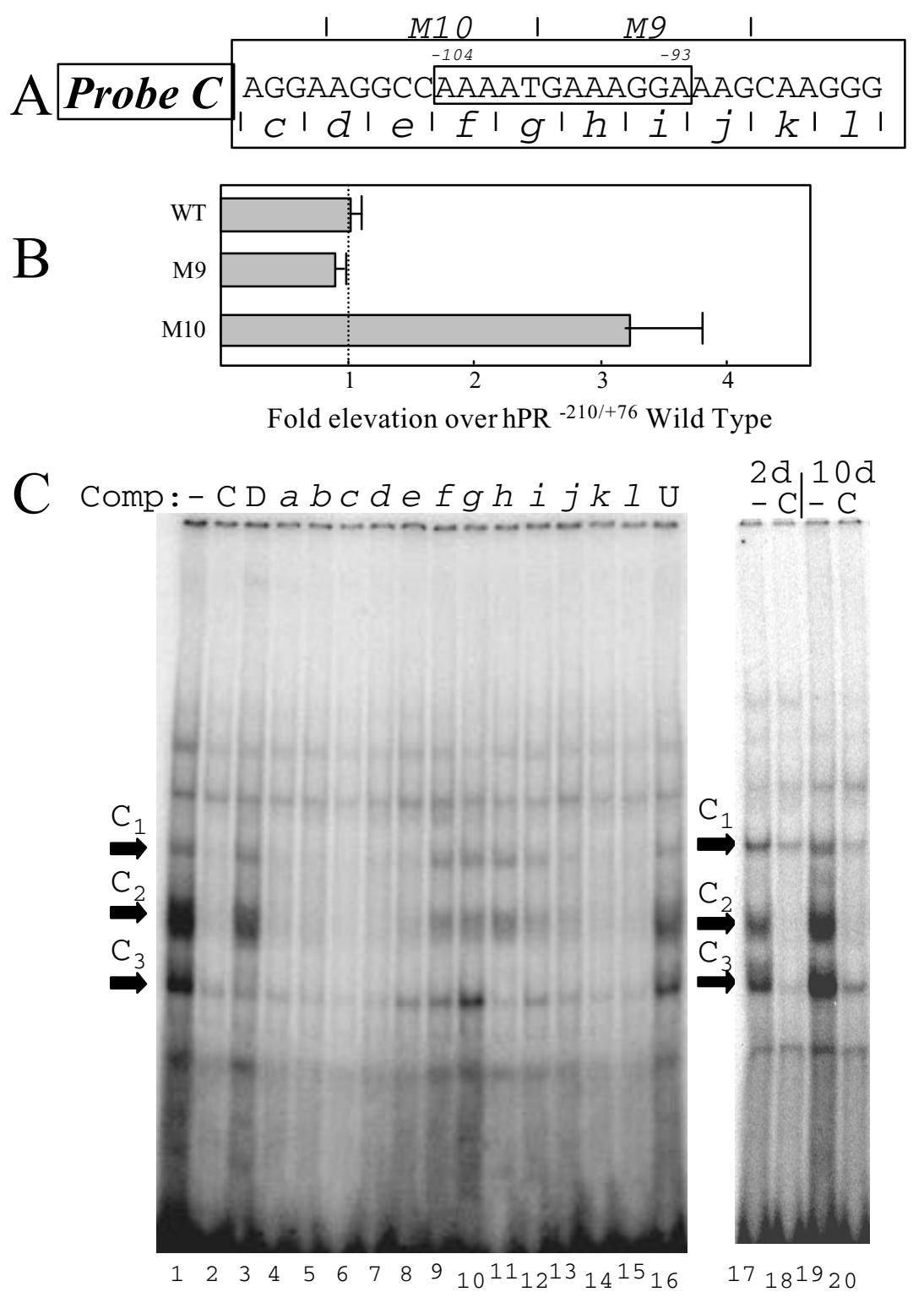

Figure 6 


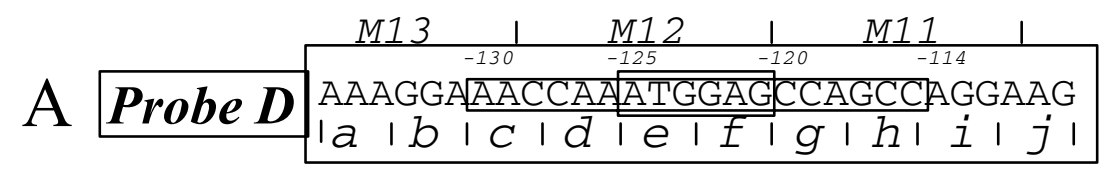

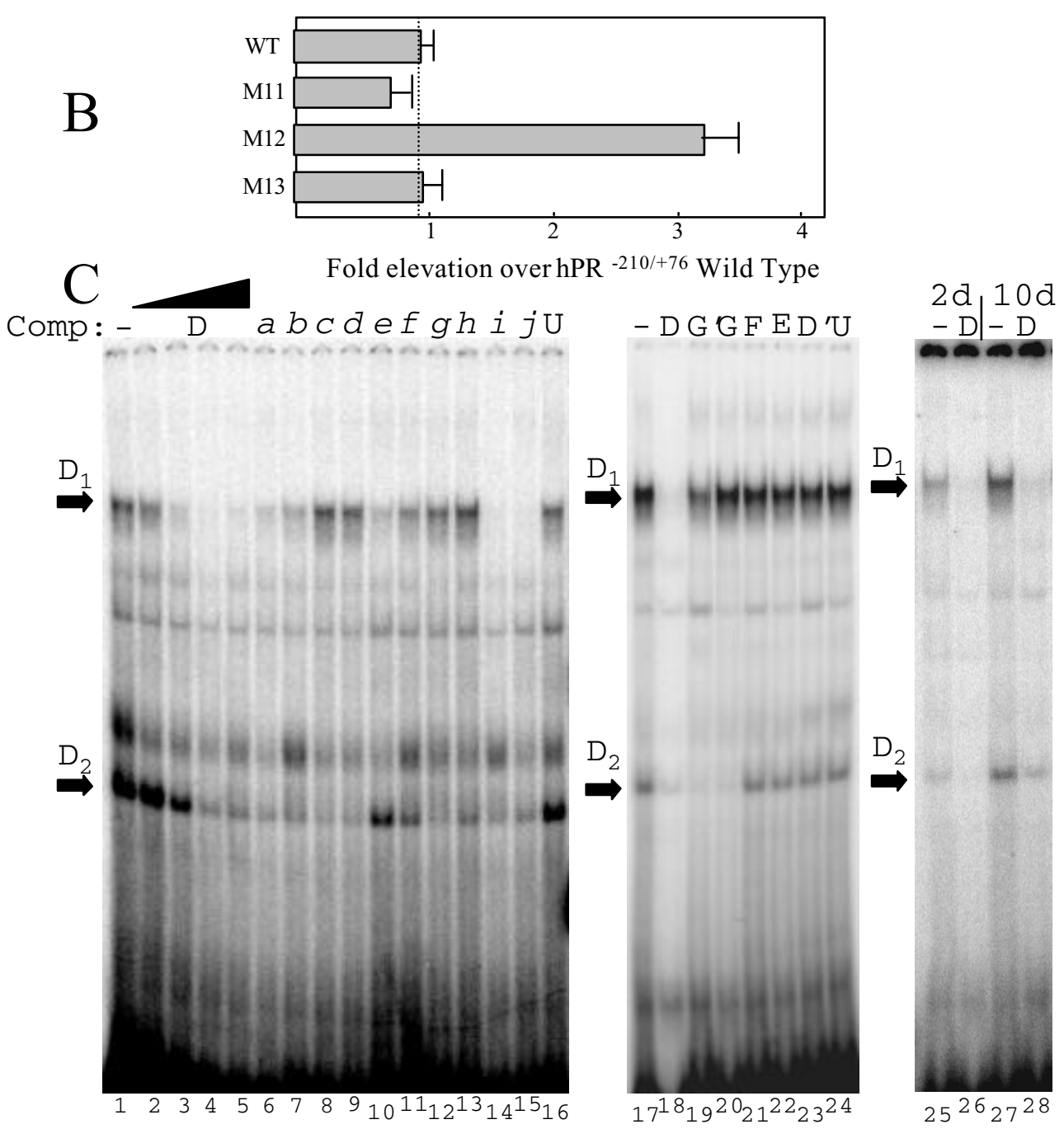

Figure 7 


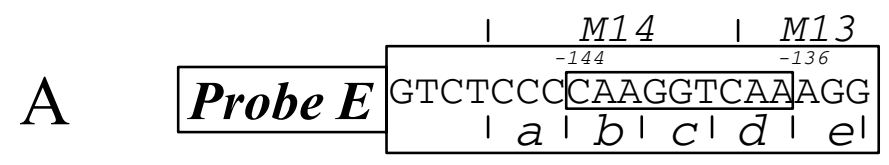

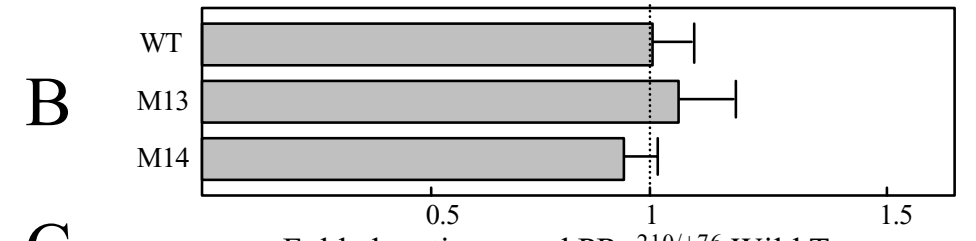

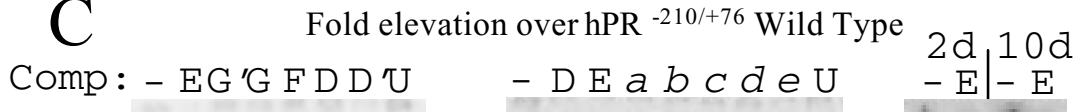

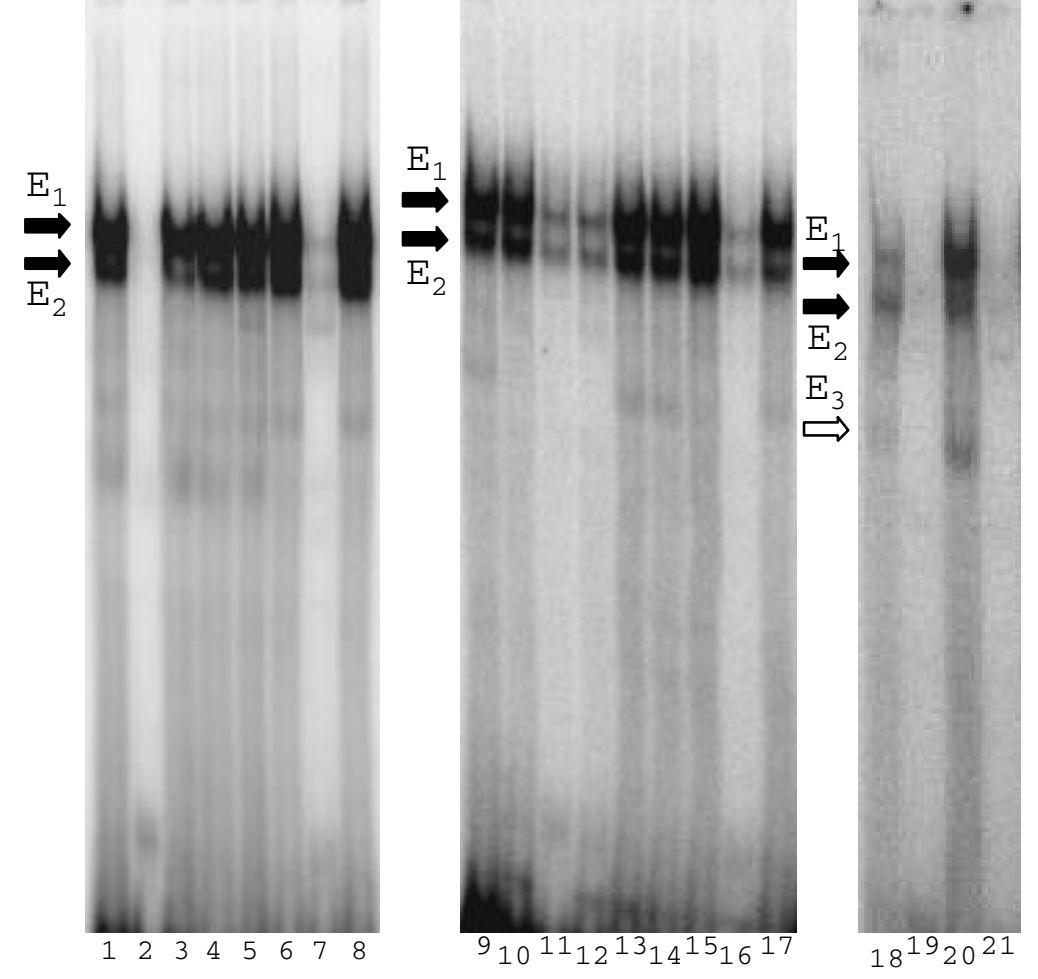

Figure 8 

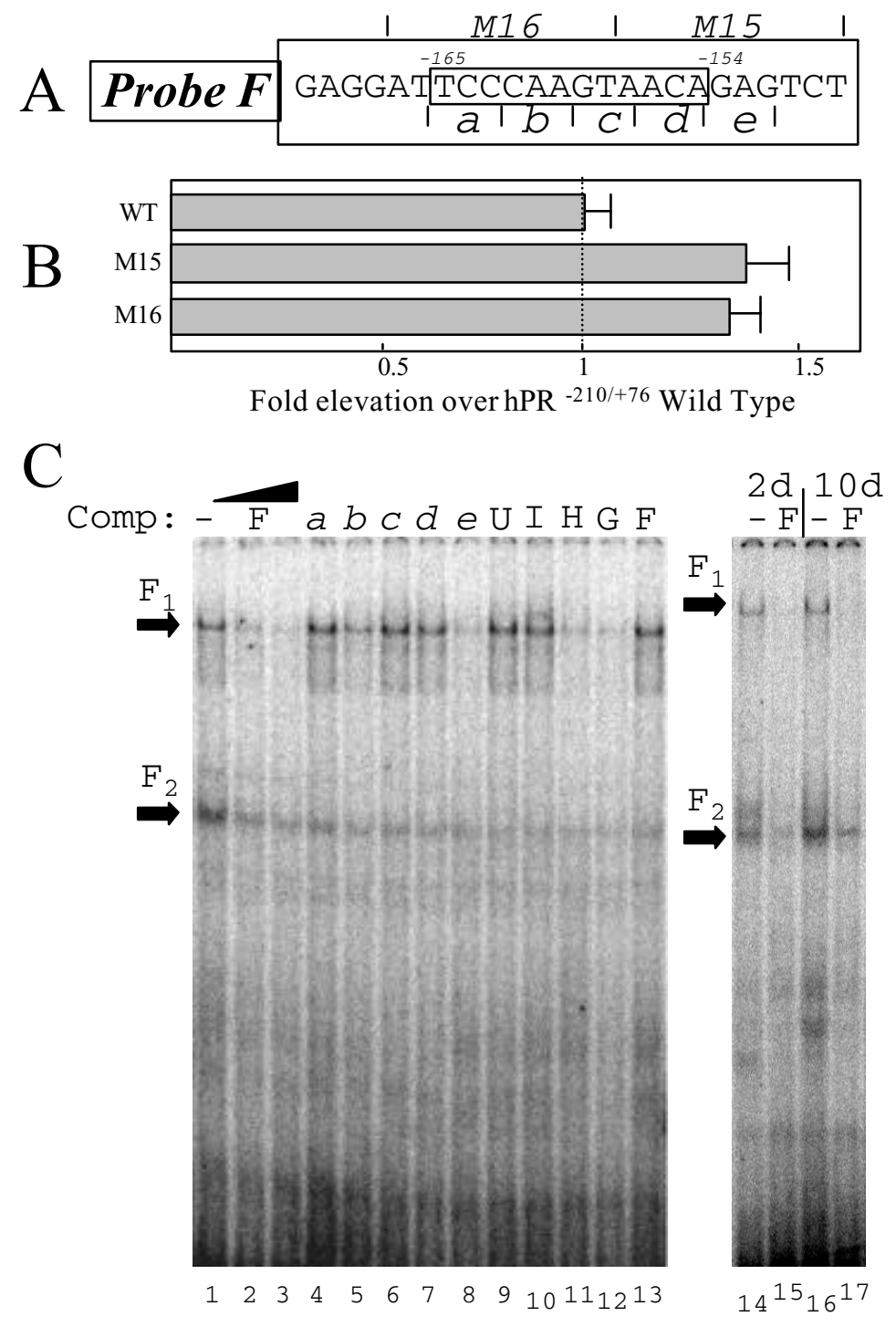

Figure 9 